\title{
GPs prescribing of strong opioid drugs for patients with chronic non-cancer pain:
}

\author{
a qualitative study
}

\begin{abstract}
\section{Background}

Chronic non-cancer pain (CNCP) is common in the UK. GPs manage most patients with such pain. Previous research has suggested that prescribing is influenced by patient and doctor factors, but less is known about the decisionmaking process involved in prescribing opioid drugs for CNCP.
\end{abstract}

\section{Aim}

To describe the factors influencing GPs prescribing of strong opioid drugs for CNCP.

\section{Design and setting}

Semi-structured interviews and a focus group of a purposive sample of GPs from a range of practice settings including male and female GPs with experience of prescribing strong opioids.

\section{Method}

Transcripts of interviews and a focus group were analysed using qualitative research methodology (thematic analysis).

\section{Results}

GPs described prescribing opioid drugs for patients with CNCP as being different from treating cancer related pain. GPs followed accepted stepwise approaches in their prescribing for CNCP. They reported difficulty in assessing the level of pain and concern over duration of use of strong opioids and their possible side effects, tolerance, and addiction. Variation in reported practice was observed, which may be linked to experience and significant events.

\section{Conclusion}

GPs in this study demonstrated a thoughtful attitude towards prescribing strong opioids for CNCP. They were aware of the difficulties of long-term strong opioid prescription. Only a few GPs had had specific training in chronic pain management and this may explain some of the variation in practice reported. GPs may benefit from training in pain assessment and long-term management of patients with CNCP.

\section{Keywords}

chronic pain; opioids; physician; prescribing patterns; primary health care.

\section{INTRODUCTION}

Chronic pain has a high prevalence throughout the world, ${ }^{1}$ and studies of the UK population have indicated a prevalence of persistent pain anywhere between $13 \%^{2}$ and $46 \%{ }^{3}$ of the study population. A followup survey of patients in Scotland indicated pain persisting for more than 4 years in $78 \%$ of those originally reporting pain. ${ }^{4}$

A European survey indicated chronic pain of moderate to severe intensity in 19\% of adult Europeans, with very few patients being seen by pain specialists and most being managed by GPs. ${ }^{2}$ Nearly half of those surveyed received inadequate pain relief. Opioid treatment has been extended to patients with chronic pain based on, albeit short-term, randomised trials demonstrating increased pain relief and increased function, ${ }^{5}$ and later systematic reviews indicated benefit to a proportion of chronic pain sufferers. ${ }^{6,7}$ Subsequently, guidelines have been developed to aid safe prescribing of long-term opioids. ${ }^{8,9}$ In recent years, however, questions as to the effectiveness and safety of long-term opioid use have been raised. ${ }^{10-12}$ Long-term follow-up of patients treated in a pain clinic setting suggested that opioid medication as currently provided is not achieving the goal of improving pain control, function, and quality of life. ${ }^{13}$

Survey data suggest that around 12\% of UK patients with chronic pain are prescribed strong opioids, mainly by GPs. ${ }^{2}$

D Seamark, PhD, FRCGP, lead research GP; C Seamark, MD, FRCGP, research GP; S Blake BSc, research associate, Honiton Research Practice, Honiton, Devon, UK. C Greaves, PhD, senior research fellow, University of Exeter medical School (Primary Care), Exeter, UK. Address for correspondence

David Seamark, Honiton Research Practice, Honiton Surgery, Marlpits Lane, Honiton, Devon, EX14 2NY.
A study of the beliefs and practice of opioid prescribing for chronic pain by GPs in the UK suggested that prescribing or not was mainly determined by personal beliefs about the appropriateness of opioids for chronic pain. Neither training nor guideline use influenced prescribing in this study. ${ }^{14}$ A further study in the UK ${ }^{15}$ concluded that $83 \%$ of GPs believe opioids are effective for chronic pain, but worry about long-term treatment, addiction, and other adverse events.

Apart from a US study that used qualitative techniques to elicit barriers to prescribing opioids to older adults with CNCP, previous studies have involved questionnaire surveys with no significant qualitative component. ${ }^{14-18}$ The study team felt this was an area where qualitative research could produce richer data about the factors that influence GP's prescribing of strong opioids for chronic pain sufferers in the UK.19

The aim of this current study was to describe the factors influencing GPs prescribing of strong opioid drugs for CNCP.

\section{METHOD}

\section{Design}

This was a qualitative study, using thematic analysis of semi-structured interviews and a single focus group to collect data from a purposive sample of GPs.

\section{Participants and setting}

A purposive sample of GPs with experience

E-mail: david.seamarkanhs.net

Submitted: 23 April 2013; Editor's response; 3 July 2013; final acceptance: 6 August 2013 (c) British Journal of General Practice. This is the full-length article (published online 25 Nov 2013) of an abridged version published in print. Cite this article as: Br J Gen Pract 2013; DOI: 10.3399/bjgp13X675403 


\section{How this fits in}

Chronic pain is common and most patients are managed in primary care. Patient and doctor factors are known to influence the prescribing of strong opioids. GPs in this study demonstrated a thoughtful and balanced approach to prescribing strong opioids. Variations in practice may be explained

of prescribing strong opioids was selected to include male and female GPs from a wide range of practice settings. Interviews took place at participants' surgeries, or place of work, or in one case, at the participant's home. The focus group took place at the home of one of the participants as part of a regular partners' meeting.

\section{Measures and procedure}

The interview schedule (Appendix 1) was developed after a review of the literature and discussion with local key informants in the pain service, hospice service, and GPs. Distinction between strong opioids and weaker opioids was made at the start of the interviews. Questions were open-ended to ensure that participants' views were elicited as much as was possible. At the end of each interview participants were asked if they felt there was anything else that needed to be covered or anything that they wished to add. The schedule was designed to elicit current prescribing practice, together with any events that might inform or affect prescribing, either positively or negatively. Potential participants were telephoned or emailed to ask if they would be willing to take part in the study. Written consent was obtained at the interview.

Audio cassettes of the interviews were transcribed verbatim and anonymised and NVivo9 qualitative data software was used to help organise the data. Thematic analysis 20,21 based on the constant comparison method ${ }^{22}$ was used to explore the data. Each transcript was read through first and initially coded. Overlapping codes were then grouped into broader categories and then further grouped into higher overarching themes. A thematic framework was developed and applied to all the data and transcripts in an iterative process. Negative cases (where opinions differed from the main emerging themes] were deliberately sought and examined to explain any discrepancies and highlight variations in opinion. Definitions for themes were developed and doubly coded until consensus was reached on coding. A reflexive analysis was also conducted by the lead researcher, consisting of notes on how their own perspective might influence the conduct of the study and interpretation of the results. ${ }^{23}$

\section{RESULTS}

Everyone who was approached consented to take part in the study. In total, there were 17 individual interviews and one focus group, consisting of five participants. The sample included newly qualified GPs and those with wider experience of prescribing opioids, both in general practice and in specialist situations, such as hospices. Practices ranged from city centre to rural and semi-rural settings also incorporating areas of high deprivation and areas with large retired populations. The GPS experience in general practice ranged from 9 months to 30 years; 15 were male and seven female. All were currently practising in Exeter and East Devon: 12 in the city centre, two in areas of high deprivation and two with a high elderly and retired population; nine semi-rural; and one locum covering urban and rural areas.

\section{Training}

Of the 22 GPs, 10 had no training in pain management or palliative care, five recalled some training during initial GP training, four reported that they had attended occasional day courses, and five declared a particular interest in the area and had attended courses or spent time in a palliative care setting:

Umm, not really l've been to occasional courses that I have chosen to go to, but nothing specific and certainly nothing before / started as a GP.'A p1

I've probably got a bit of an interest in palliative care and have done more than the average number of courses. But in terms of specific, specialised training, no.'D p1

"I had no training at all as an undergraduate or as a GP trainee in pain management. F p1

\section{Emergent themes}

Chronic non-cancer pain is seen as different from cancer pain. All participants had prescribed opioids for CNCP, although one had stopped doing this. All GPs described the use of a stepwise or ladder method for prescribing opioid medication ${ }^{24}$ for cancer pain, starting with low doses and gradually 
working through stronger medications with an aim of keeping the patient pain free:

I suppose the sort of pathway really is to start off with simple analgesia then you progress down through the stronger, what I would call simple analgesics, through, you know, like paracetamol, down through perhaps tramadol and I think probably then my next line if it's more severe pain would be to drift into the morphine-based drugs. B p2

For CNCP, deciding to initiate opioid treatment was less straightforward, with many considerations.

GPs would often say that, in theory, prescribing for CNCP is the equivalent of prescribing for cancer pain, but this would then be qualified by reluctance to move onto stronger opioids for chronic pain. Other avenues, such as the pain clinic or antidepressants may be explored first and there was recognition that total pain relief may not be achieved for the CNCP patient:

I don't regard them as the same, whereas with one of them your aim always in progressive malignant disease is to get complete relief of pain as best you can, umm, and for that you will need increasing amounts of morphine over a finite period of time. For chronic pain in someone with a non-terminal type of illness you've got to weigh up what you are giving them in the long term, what are the potential side effects, is there an issue with addiction and you're not going to just be increasing ... For chronic pain, non-malignant pain, I think there has to be an acceptance that you are not necessarily going to get them pain free because they've got the rest of their lives to live as well ... so your two end points are different.'D p2

If I know that someone is terminally ill I am probably less inhibited about the scale of opiate use ... but when you know that someone is going to go on and on suffering from the pain of whatever cause it is that they've got, that can make it very difficult. A p2

'There is always a worry at the back of my mind that I may over prescribe the opiate but I'm having to be careful to titrate the dose of the opiate with the pain that the patient has got. If I'm not careful about that the patient may end up having too much opiate and you know I do feel that is probably a problem, something I wouldn't want to have myself so I wouldn't want to do for somebody under my care. 'A p3

One GP explained that, although in theory prescribing is reasonable, in practice he was a little reluctant to prescribe:

'I think my brain tells me that there is no problem, although you know, life in general makes you think that you must be a bit careful but I don't think there is a reason why we shouldn't put somebody on longterm opiates if the need is there. 'B p3

Another commonly stated concern was the potential length of time patients could theoretically spend taking opioids if started at a younger age:

'The aims are different, you can be dealing with these patients for 30, 40 years still ... . D p4.

'I mean when you've got somebody who has actually got some progressive cancer you'd probably go down the steps or up the steps quicker than you do with Mrs Bloggs who is going to have arthritic pain for 30 years, and you know she will so you do your best to try and muddle along with something of a lesser strength.'B p2

Difficulties in assessing pain. GPs expressed having difficulty assessing the level of CNCP land therefore titrating the dose correctly). They also expressed concern about the possible secondary gains of obtaining opioids or accessing financial benefits:

C p2: 'The concern would be is this pain real, or is it just put on to obtain opioid?'

Interviewer: 'How do you deal with that?'

C p2: 'On an individual basis, I mean, an assessment of the pain and whether I think it's genuine or not. I think it's very difficult; it's something I'm currently dealing with at the moment, and not very successfully.'

'The pain is what the patient says hurts, ... But how do we judge that, and that's when it gets very difficult so I think the hardest group that I have is drug addicts and malingerers, people who are faking pain ... I can think of one very clear malingerer I've got at the moment with chronic back pain. His agenda is not about getting strong pain killers his agenda is about persuading the DLA to give him full disability living allowance ... .' $\mathrm{G}$ p $4 / 5$ 
Some felt that they should be exploring other ways of managing pain, including psychological treatments and alternative medication approaches and delivery pathways:

Well people without a specific diagnosis or younger people who hadn't worked for a long time without any definite diagnosis so you feel there may be other things going on, I might be a bit concerned about putting them on a long-term opioid, because I wouldn't necessarily know what I was treating, I might send them to pain clinic for psychological assessment.' L p3

I suppose the concern is are you adequately addressing their pain needs, have you looked at alternatives to managing their pain with ever and ever increasing doses of opiate use.' H p3

I still have this general rule that has increased over the years that l've been in general practice that I will only take the opioid route when I absolutely have to. D p5

Concerns around tolerance and addiction. The most common concern cited was the potential for addiction. This was sometimes combined with concern for tolerance (habituation), causing a worry that the dose might increase over time and the possibility that the patient may require that medication over many years:

'There's always the feeling that it's going to be more difficult for somebody to stop taking opioids or needing to take more, but it would depend on the personality. Because chronic pain is related to having other problems, mainly psychological problems, one wouldn't want to hand it out willy nilly to people who might have psychological problems as well and would be more likely to become dependent.' L p3

Yes I do worry about addiction and if someone has a pain, umm, I understand that addiction is not supposed to happen if you use the opiate for pain and that if the opiate relieves the pain the patient is not supposed to get addicted to it. It's very hard for me to believe that is true. I am probably more inhibited where the patient is not terminal because I have that sort of nebulous fear in the back of my mind that I am going to al cause opiate habituation and b) cause addiction.' A p3
Where there was a strong interest in palliative care or pain management this appeared to facilitate prescribing in four participants, who reported less concern about prescribing strong opioid medication for CNCP:

I think there's a lot of unreasonable fears, the biggest one being addiction and I think it's a grossly, grossly overstated concern, addiction. In my practice l've yet to see the patient who was put on opiates for benign pain who is addicted. 'F p3

'No I really don't have a problem with that [addiction]. I think that one has to consider that you have got to put yourself in the patient's position. Would you want to go through life being denied something because there was a theoretical risk of addiction, and the answer would be no, if it improves your quality of life, that's what you want.' $\mathrm{M} \mathrm{p} 2 / 3$

GPs demonstrated awareness about prescribing to patients with a history of substance misuse or what was termed an addictive personality. However, this did not necessarily prevent the prescribing of opioids:

I'm always more concerned about people who have an abusive or abusing personality, or been abusive of other drugs in the past, particularly concurrent abuse of alcohol or other drugs. 'F p8

'I think if someone's history shows that they have an addictive personality, whether it be street drugs, alcohol, smoking pot, whatever that theoretical concern is, but the patients l've used opiates for in noncancer are nearly always the elderly with joint pain and I don't have any concerns about them, no.' $\mathrm{N} \mathrm{p3}$

Effect of experience and events. For many, experience facilitated prescribing, giving confidence over time:

I suppose, the way I behave now prescribing for everything is a sort of rather woolly, nebulous product of everything I've done, particular experiences of dealing with pain.' A p7

'You just pick it up over the years, so I'm sure l've been moulded by the successes and the failures which have come my way in 27 years of general practice, yeah sure we all learn on the hoof, don't we?' B p7 
I'm not as slow to treat with opiates now as I was 30 years ago, and I'm sufficiently bigheaded that even if another doctor with the title consultant thought it was inappropriate I'd still go ahead and do it. If there was no other way of controlling someone's pain, and having discussed it with the patient, I'm prepared to do it.' $\mathrm{N} \mathrm{p4}$

However, not all events were positive, and these could have a negative effect on prescribing:

Well, I guess that the previous experience of it being quite a taboo thing.' I p3

I think everybody's fingers get burnt with people who you give the opioids to with a more trusting attitude than maybe you should have and the problem has quickly come back to you with needing more and more opioids. 'R p6

For one GP in particular, a bad experience has resulted in his never prescribing opioids for chronic pain:

One of the doctors used to use quite a lot of low dose MST in older people with arthritis, umm, and I certainly hadn't considered doing this and I thought well it might be worth a try and there's one lady in particular that I tried it on in whom it was a complete disaster and it just made her so ill and from reasons that I couldn't, we just couldn't get her off it and she was ill on it and was worse when we tried to get her off it and you don't need many of those. 'D p8

Participants were asked whether the Shipman case had had any effect on their prescribing of strong opioids. All the participants indicated that Shipman had not affected their prescribing:

No, because from my point of view Shipman was a very clear aberration of care and it doesn't really influence.' $\mathrm{H} \mathrm{pb}$

Cost. There were mixed responses to the issue of cost. Some participants did not consider it at all, simply prescribing what was needed, regardless of how much it cost. Others felt it was important to bear in mind how much some of the preparations cost, particularly patches, which can be expensive:

Well I have to say I'm hopeless on cost because I never know, patches are more expensive than anything else. It personally wouldn't make a hap'oth of difference to me, if somebody needed something then I would use it and I don't think I'm really aware of the relative costs, so no, I don't think actually cost is very high on my priority.'B p8

'These are not cheap treatments at all, and you could potentially be doing it for 10, 20 years and you know, there may be a rise in patient numbers doing this type of treatment in a few years' time, I think it's really important.' $\mathrm{C}$ p4

\section{DISCUSSION}

\section{Summary}

This study brings new insights, being the first qualitative research on this topic in a UK setting, into what a GP thinks about when considering prescribing strong opioid drugs for patients with CNCP. GPs in this study demonstrated a balanced approach to prescribing despite wide variation in experience and training. GPs used a stepwise strategy developed for cancer pain control, ${ }^{24}$ which is in line with published guidelines for chronic pain control.8,9 In this study few GPs had received any specific training in prescribing for $\mathrm{CNCP}$, with training usually undertaken as a result of personal interest in the subject. Experience in palliative care appeared to inspire more confidence in prescribing. Variations in practice were reported. Previous experience of prescribing and significant events had both a positive and a negative influence.

Although the potential benefits of opioids were acknowledged, GPs saw CNCP as being different from cancer pain and demonstrated a more cautious approach to prescribing. They tried to balance potential positive and negative outcomes. These included benefits of pain relief versus the length of time prescriptions may be required and concerns over addiction and tolerance. One area of concern was the difficulty in distinguishing true pain from possible secondary gains such as obtaining opioids or securing financial benefits, and this indicates an area where training may be of help. Participants' prescribing had not been affected by the Shipman case.

\section{Strengths and limitations}

The qualitative methodology was designed to elicit in-depth, personal views and experiences of a small number GPs and as such cannot be seen as generalisable. The study was situated in the south west of the UK, and as such does not claim to be representative of the whole of the UK. The main strength of this study is that it provides a more in-depth exploration of 
the strategies and underlying reasoning behind GPs' opioid prescribing decisions, than previous survey-based studies.

\section{Comparison with existing literature}

GPs treat most patients with CNCP and have to balance the evidence that opioids may help such patients ${ }^{6}$ against reports in the literature that such drugs may in fact do harm. ${ }^{10,12}$ Prescribing opioids is a complex decision and is influenced by physician and patient factors. A qualitative US study concluded that primary care physicians perceived multiple barriers to prescribing opioids, including fear of causing harm, the subjectivity of pain, lack of education, and concerns around opioid misuse. ${ }^{19}$ A Canadian study found that family physicians had a low comfort level when prescribing opioids possibly related to lack of education and fear of regulatory scrutiny. ${ }^{25}$ Another study found that physicians practice in prescribing opioids appeared to be influenced most by patient's nonverbal communication of pain, distress, and suffering. ${ }^{26}$ UK studies suggest that patient attitudes and beliefs about pain medication are associated with adherence to medication and may determine their own opioid consumption. ${ }^{27,28}$

Previous work in the UK ${ }^{14,15}$ indicated that a one-quarter to one-third of GPs did not prescribe opioids for CNCP. This is in contrast with the present study, which found that only one of 22 GPs sampled would not prescribe opioids for CNCP. McCracken et all ${ }^{15}$ reported a reluctance of GPs to prescribe strong opioids for CNCP when compared with treating cancer pain, with concerns expressed about longterm commitment, addiction, and other adverse effects. These observations are borne out in the current study with GPs balancing the positive and negative aspects of opioid prescribing. Hutchinson et $a l^{4}$ looked at predictors of opioid prescribing and concluded that prescribing was mainly determined by personal beliefs about the appropriate use of opioids for the problem of CNCP. This study demonstrated that GPs interviewed believed in the benefits of opioids and after a broad consideration of many factors did prescribe. Concerns about the duration of prescribing are borne out in the literature with a Danish study showing $60 \%$ of patients being maintained on opioids for 10 years or more. ${ }^{13}$

The true level of opioid addiction varies from $0 \%$ to $50 \%$ in studies on prescribing in chronic pain, ${ }^{29}$ and current guidelines mention addiction as a potential problem. The GPs in this study were unaware of current guidelines such as those published by the British Pain Society, but demonstrated awareness of the problem and associated clinical conditions with addiction.

A number of studies conclude that further training is required, ${ }^{25,30}$ and the two UK studies concluded that GPs had little training in opioid prescribing and that effective prescribing in CNCP may be enhanced by training. ${ }^{14,15} \mathrm{~A}$ recent training intervention for GPs including education on opioid guidelines for chronic pain demonstrated increased knowledge of prescribing and reduced concerns but did not change prescribing behaviour or GP wellbeing. ${ }^{31}$ The GPs in this study appeared to demonstrate adequate knowledge of risks and benefits of opioid prescribing, but struggled to assess the extent of pain experienced by patients and how to deal with the consequences of long-term prescribing of opioids. There is growing recognition that analgesic drugs work well but only in a small proportion of patients, and that pain relief should be measured in individual patients with alternative strategies being used when analgesic failure occurs. ${ }^{32}$ Taken with the finding of this study there would seem to be a need for future research on GP assessment of pain and recognition of failure of opioid pain control.

\section{Implications for research and practice}

There are an increasing number of patients with CNCP. There is a need to establish which aspects of training and managing this long-term condition will be useful for GPs. GPs in this study demonstrated a thoughtful attitude to prescribing opioid drugs for CNCP, using stepwise strategies that are in line with current guidance. They were aware of the need to balance the analgesic benefits of long-term strong opioid use against the possible side effects of the drugs, tolerance, and addiction. Only a few GPs had had specific training in chronic pain management and this may explain some of the variation in practice reported. GPs may benefit particularly from further training on pain assessment and long-term management of patients with CNCP, and this would be an area for further research. 


\section{REFERENCES}

1. Gureje O, von Korff M, Simon GE, Gater R. Persistent pain and well-being: a World Health Organization Study in Primary Care. JAMA 1998; 280: 147-151.

2. Breivik $H$, Collett $B$, Ventafridda $V$, et al. Survey of chronic pain in Europe: Prevalence, impact on daily life, and treatment. Eur J Pain 2006; 10: 287-333.

3. Elliott AM, Smith BH, Penny Kl, et al. The epidemiology of chronic pain in the community. Lancet 1999; 354: 1248-1252.

4. Elliott AM, Smith BH, Hannaford PC, et al. The course of chronic pain in the community: results of a 4-year follow-up study. Pain 2002; 99: 299-307

5. Kalso E, Edwards JE, Moore RA, McQuay HJ. Opioids in chronic non-cancer pain: systematic review of efficacy and safety. Pain 2004; 112: 372-380.

6. Noble M, Tregear SJ, Treadwell JR, Schoelles K. Long-term opioid therapy for chronic noncancer pain: a systematic review and meta-analysis of efficacy and safety. J Pain Symptom Manage 2008; 35: 214-228.

7. Noble M, Treadwell JR, Tregear SJ, et al. Long-term opioids management for chronic noncancer pain. In: Cochrane Collaboration. The Cochrane Library. Issue 1. Oxford: Update Software, 2010.

8. The British Pain Society. Opioids for persistent pain: Good practice, 2010. http:// www.britishpainsociety.org/book_opioid_main.pdf. (accessed 17 October 2013).

9. Chou R, Fanciullo GJ, Fine PG, et al. Clinical guidelines for the use of chronic opioid therapy in chronic noncancer pain. J Pain 2009; 10: 113-130.

10. Ballantyne JC. Opioids for chronic pain: taking stock. Pain 2006; 125: 3-4.

11. Eriksen J, Sjøgren P, Bruera E, et al. Critical issues on opioids in chronic noncancer pain: An epidemiological study. Pain 2006; 125: 172-179.

12. Dhalla IA. Opium, opioids, and an increased risk of death. BMJ 2012; 344: 9

13. Jensen MK, Thomsen AB, Højsted J. 10-year follow-up of chronic nonmalignant pain in patients: Opioid use, health related quality of life and health care utilization. Eur J Pain 2006; 10: 423-433.

14. Hutchinson K, Moreland AME, Williams ACdeC, et al. Exploring beliefs and practice of opioids prescribing for persistent non-cancer pain by general practitioners. Eur J Pain 2007; 11: 93-98.

15. McCracken LM, Velleman SC, Eccleston C. Patterns of prescription and concern about opioid analgesics for chronic non-malignant pain in general practice. Prim Health Care Res Dev 2008; 9: 146-156.

16. Bhamb B, Brown D, Hariharan J, et al. Survey of select practice behaviors by primary care physicians on the use of opioids for chronic pain. Curr Med Res Opin 2006; 22: 1859-1865
17. Nwokeji ED, Rascati KL, Brown CM, Eisenberg A. Influences of attitudes on family physicians' willingness to prescribe long-acting opioid analgesics for patients with chronic non-malignant pain. Clin Ther 2007; 29(suppl): 2589-2602.

18. Wolfert MZ, Gilson AM, Dahl JL, Cleary JF. Opioid analgesics for pain control: Wisconsin physicians' knowledge, beliefs, attitudes, and prescribing practices. Pain Med 1010; 11: 425-434.

19. Spitz A, Moore AA, Papaleontiou M, et al. Primary care providers' perspective on prescribing opioids to older adults with chronic non-cancer pain: A qualitative study. BMC Geriatrics 2011; 11: 35.

20. Braun V, Clarke V. Thematic analysis. In: Cooper H, editor. The APA Handbook of research methods in psychology: Vol 2 Research designs. Washington DC: American Psychological Association, 2012: 55-91.

21. Bryman J. Social Research Methods. Oxford: Oxford University Press, 2001.

22. Glaser BG, Strauss AL. The discovery of grounded theory: strategies for qualitative research. New York, NY: Aldine; 1967.

23. Strauss A, Corbin J. Basis of qualitative research: Techniques and procedures for developing grounded theory. 2nd ed. Thousand Oaks, CA: Sage, 1998.

24. World Health Organization. WHO's pain ladder for adults. http://www.who.int/ cancer/palliative/painladder laccessed 17 October 2013).

25. Scanlon MN, Chugh U. Exploring physicians' comfort levels with opioids for chronic noncancer pain. Pain Res Manage 2004; 9: 195-201.

26. Turk DC, Okifuji A. What factors affect physicians' decisions to prescribe opioids for chronic noncancer pain patients? Clin J Pain 1997; 13: 330-336.

27. Blake S, Ruel B, Seamark C, Seamark D. Experiences of patients requiring strong opioid drugs for chronic pain: a patient initiated study. Br J Gen Pract 2007; 57: 101-108.

28. Rosser BA, McCracken LM, Velleman SC, et al. Concerns about medication and medication adherence in patients with chronic pain recruited from general practice. Pain 2011; 152: 1201-1205

29. Højsted J, Sjøgren P. Addiction to opioids in chronic pain patients: a literature review. Eur J Pain 2007; 11: 490-518

30. Speechley M, Moulin DE, Clark AJ, Morley-Forster PK. Attitudes toward opioid use for chronic pain: a Canadian physician study. Pain Res Manage 2003; 8: 189-194

31. McCracken LM, Boichat C, Eccleston C. Training for general practitioners in opioid prescribing for chronic pain based on practice guidelines: a randomized pilot and feasibility trial. J Pain 2012; 13: 32-40.

32. Moore A, Derry S, Eccleston C, Kalso E. Expect analgesic failure; pursue analgesic success. BMJ 2013; 346: f2690 doi: 10.1136/bmj.f2690. 


\section{Appendix 1. Topic guide for interviews}

- Introduction

- Who I am and reason for interview.

- How long a GP?

- Identify any specific training in pain management and/or palliative care

- How do you manage pain associated with progressive diseases such as cancer or end stage organ disease?

- Strategy for prescribing, that is, stepwise progression, WHO guidelines.

- Strategy for chronic pain, that is, musculoskeletal, multiple sclerosis, regional pain syndrome.

- Are both categories of pain treated the same?

- Is non-cancer chronic pain (NCCP) a more problematic group? If so, why

- Do you have any concerns about prolonged opioid use, that is:

- Addiction (physical, psychological)

- Diversion

- Tolerance

- Are there any particular groups of patients who cause concern?

- Previous substance misuse

- Criminality

- Vulnerable groups, that is, single parent with children

- Other members of the household

- Other medical conditions

- Use of other resources

- Pain clinic

- Palliative care consultant

- Other colleagues/GPs

- Physiotherapist

- Hospice nurse

- Complementary/alternative medicine

- Has previous experience shaped your attitudes in any way towards prescribing?

- Professional experience

- Personal experience

- Have recent events shaped your attitudes in any way towards prescribing?

- Shipman

- Regulatory changes (revalidation)

- Controlled drugs regulations

\section{Specific products prescribed}

- Cocodamol

- Coproxamol

Moderate groups

- Codeine

- Dihydrocodeine

- Tramadol

Strong group

- Morphine

- Elixir (Oramorph)

- Tablets (Sevredol)

- Slow release (caps/tabs, MST, Zomorph]

- Oxycodone

- Patches

- Fentanyl

- Buprenorphine (Butrans)

\section{Strategy for using strong opioids}

- Does the delivery system affect prescribing? That is, when would you use oral products over the patch?

- How important is cost, bearing in mind the length of the treatment? 